\title{
Comparison of dietary supplementation with lutein diacetate and lutein: a pilot study of the effects on serum and macular pigment*
}

\author{
John Landrum ${ }^{1 凶}$, Richard Bone2, Vanesa Mendez ${ }^{1}$, Anisley Valenciaga ${ }^{1}$ and Darwin Babino ${ }^{1}$ \\ 1Department of Chemistry and Biochemistry, Florida International University, Miami, FL, USA; 2Department of Physics, Florida International \\ University, Miami, FL, USA
}

\begin{abstract}
The responses of subjects taking a $20 \mathrm{mg} /$ day lutein diacetate supplement were compared with that for a 20 $\mathrm{mg} /$ day crystalline lutein or a placebo. Ten subjects, assigned to each of three groups, lutein diacetate (group $1)$, lutein (group 2), and a placebo (group 3), were supplemented for 24 weeks. Groups 1 and 2 consumed a dose equivalent to $20 \mathrm{mg}$ per day of free lutein. Serum samples, collected at baseline, and at weeks 6, 12, 18, and 24 were analyzed by HPLC. Macular Pigment Optical Density (MPOD) was obtained by heterochromatic flicker photometry at baseline and weeks 6, 12, 18 and 24. Results: The average serum lutein concentrations for weeks 6 to 24 expressed as a ratio to the baseline value ( \pm S.D.) were $5.52 \pm 2.88$ for group $1,4.43 \pm 1.61$ for group 2 , and $1.03 \pm 0.25$ for group 3 . The median rate of macular pigment increase (milli-absorbance units/week) for groups 1, 2, and 3 were $2.35,1.55$, and $0.19 \mathrm{mAU} / \mathrm{wk}$, respectively. $P$-values for these serum and MPOD increases are both highly significant when compared to placebo. The average serum response was about $25 \%$ higher for group 1 compared with group 2 and, the median MPOD response was $52 \%$ higher for group 1 than group 2. $P$ values calculated for the differences in these increases were, $p=0.066$, marginally significant, for serum, and $p$ $=0.09$ approaching significance, for MPOD.
\end{abstract}

Key words: lutein, lutein diacetate, macular pigment, macular pigment optical density, dietary supplement

Received: 17 October, 2011; accepted: 01 March, 2012; available on-line: 17 March, 2012

\section{INTRODUCTION}

Lutein is an important nutrient with a recognized role in providing protection of the macula from photo-oxidative stress and evidence indicates that lutein protects the retina from the on-set of age related macular degeneration (Bone \& Landrum, 2010; Landrum \& Bone, 2001; Mares et al., 2011; Norkus et al., 2010; SanGiovanni et al., 2007; Schalch et al., 2010). Bioavailability of different forms of lutein has been the subject of numerous studies (Benzie et al., 2006; Bowen et al., 2002; Chung et al., 2004; Mamatha \& Baskaran, 2011; Roodenburg et al., 2000). The principal formulations that have been commercially available for many years include either lutein fatty acid diesters or crystalline lutein (Bowen et al., 2002). Typically these components are formulated as suspensions or emulsions in vegetable oil but may also be incorporated, using specialized formulation technologies, into agar or gelatin microbeadlets, for example, DSM Actilease ${ }^{\mathrm{TM}}$ or
Cognis Xangold ${ }^{\mathrm{TM}}$. Since only free, unesterified lutein is detectable in serum, it is evident that the esterase activity readily and efficiently cleaves lutein esters during the absorption process (Granado et al., 1998). To date, studies of the effect of esterification of lutein used in supplements on the absorption/bioavailability has been varied results (Bone \& Landrum, 2010, Bowen et al., 2002; Norkus et al., 2010). It has been suggested that the more lipophilic diesters may rapidly equilibrate into micelles formed by dietary fat and bile salts within the gut. This study was conducted to compare responses of human subjects to a dietary lutein formulation containing micellar lutein diacetate ester to that of a similar formulation containing unesterified lutein in a vegetable oil suspension. Lutein diacetate represents a single substrate for absorption possessing a well defined composition in contrast with the complex composition of extracted fatty acid diesters present in the marigold oleoresin. It was anticipated that the lutein acetate diester should differ in its efficiency of absorption compared to unesterified lutein. This study was conducted to test this hypothesis. The endpoints for this study were serum lutein and macular pigment optical density (MPOD) changes.

\section{METHODS}

The thirty volunteers who participated in this study were recruited from the University population in accordance with the IRB guidelines. The thirty volunteers were randomly divided into three groups of ten subjects each and were given a 24 week supply of gel caps containing lutein diacetate (group 1), lutein (group 2), or a placebo (group 3). Neither subjects nor researchers were informed as to which product they were consuming. The lutein diacetate ingredient used in group 1 was prepared by acetylation of free lutein with acetic anhydride obtained after the saponification process of marigold oleoresin which normally contains little or no diacetate. The lutein diacetate was formulated into micelles to facilitate bioavailability (Olvera \& Quiroga, 2008). Each of the supplements contained a dose equivalent to $20 \mathrm{mg}$ of free lutein per day. Serum samples were collected at baseline, and at weeks 6, 12, 18, and 24, and analyzed by HPLC using methods previously described elsewhere (Bone et al., 2003; Landrum et al., 1997). MPOD meas-

\footnotetext{
e-mail: landrumj@fiu.edu
}

* Presented at the 16th International Symposium on Carotenoids, 17-22 July, 2011, Kraków, Poland

Abbreviations: MPOD, macular pigment optical density, mAU/wk, milli-absorbance units/week. 


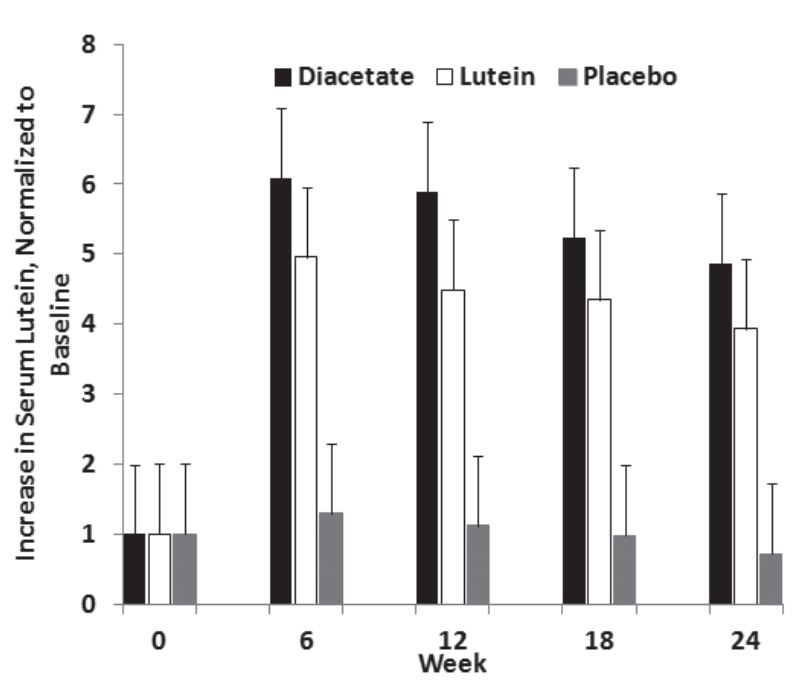

Figure 1. Average serum lutein increases observed for each group (black, diacetate; open, lutein; grey, placebo) normalized relative to baseline.

Error bars represent standard deviation calculated for the response in each group.

Table 1. Average serum concentration \pm S.D. at baseline and the average increase in the concentration for each of the three groups ${ }^{\dagger}$.

\begin{tabular}{lcc}
\hline Group & $\begin{array}{c}\text { Baseline serum } \\
\text { lutein concentration } \\
(\mu \mathrm{g} / \mathrm{ml})\end{array}$ & $\begin{array}{c}\text { Average concentration } \\
\text { increase }(\text { weeks 6-24) } \\
(\mu \mathrm{g} / \mathrm{ml})\end{array}$ \\
\hline 1. Diacetate & $0.100 \pm 0.025^{*}$ & $0.458 \pm 0.061$ \\
2. Lutein & $0.128 \pm 0.057$ & $0.425 \pm 0.092$ \\
3. Placebo & $0.167 \pm 0.048$ & $0.007 \pm 0.063$ \\
\hline
\end{tabular}

*significant difference at baseline from placebo, $p=0.0005$; the difference between the average serum concentrations for weeks 6-24 and baseline for each group.

urements were also obtained on these occasions by heterochromatic flicker photometry (Bone et al., 2003).

\section{RESULTS}

The average increase in serum lutein concentrations for the three supplementation groups at weeks 6,12 , 18 , and 24 were normalized to baseline (week 0 ) and are shown in (Fig. 1). Table 1 presents the baseline lutein serum concentrations for each group and the average increase in concentration for each supplement group aver-

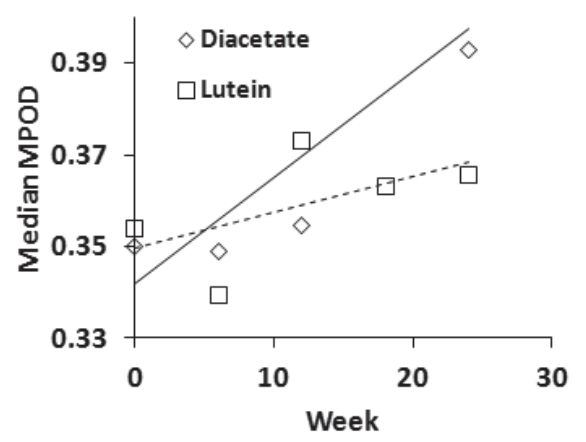

Figure 2. The median MPOD for the diacetate (filled circle, dashed line) and the lutein (open circles, solid line) supplement groups.
Table 2. Mean MPOD \pm S.D. at baseline (week 0 ) prior to supplementation, and at week 24.

\begin{tabular}{lcc}
\hline \multirow{2}{*}{ Group } & \multicolumn{2}{c}{ Mean MPOD $( \pm$ S.D.) } \\
\cline { 2 - 3 } & Week 0 & Week 24 \\
\hline 1. Diacetate & $0.370 \pm 0.146$ & $0.405 \pm 0.146$ \\
2. Lutein & $0.354 \pm 0.108$ & $0.387 \pm 0.124$ \\
3. Placebo & $0.491 \pm 0.169^{*}$ & $0.485 \pm 0.162$ \\
\hline
\end{tabular}

*MPOD at baseline was significantly different from groups 1 and 2 , $p>0.005$.

Table 3. Rates of increase in MPOD (mAU/week) for each group, comparing the means and the medians.

Minimum and Maximum are the range of the rates observed in each group.

\begin{tabular}{lcccc}
\hline \multirow{2}{*}{ Group } & \multicolumn{2}{c}{ Rate of MPOD Increase } & \multicolumn{2}{c}{ Range } \\
\cline { 2 - 5 } & Mean $( \pm$ S.D.) & Median & Min & Max \\
\hline 1. Diacetate & $1.92 \pm 1.43$ & 2.35 & 0.04 & 5.10 \\
2. Lutein & $1.69 \pm 1.75$ & 1.55 & -0.80 & 5.10 \\
3. Placebo & $-0.75 \pm 3.03$ & 0.19 & -8.70 & 1.90 \\
\hline
\end{tabular}

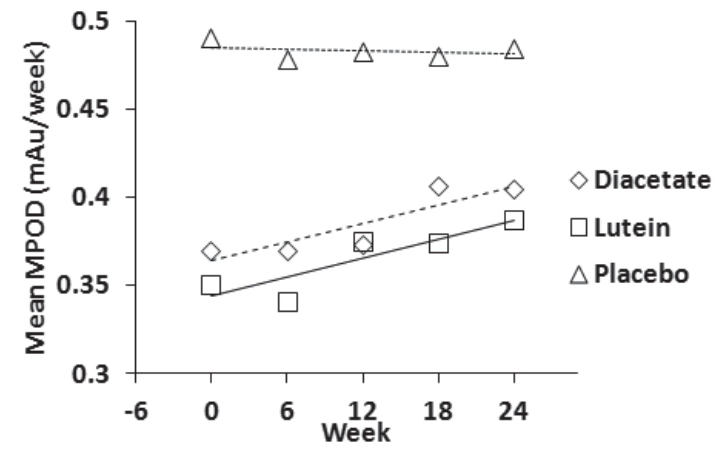

Figure 3. Mean rate of change of MPOD (represented by slopes) pinned to baseline MPOD; diacetate (dashed line), lutein (solid line) and placebo (dotted line).

aged between weeks six and twenty four. The average concentration $( \pm$ S.D.) of serum lutein for weeks 6 to 24 was $5.52 \pm 2.88$ times that of baseline for the group $1,4.43 \pm 1.61$ times that of baseline for the group 2 and $1.03 \pm 0.25$ times that of baseline for the placebo group (group 3). As observed in previous studies, $p$-values for serum increases for both lutein supplements compared to placebo were highly significant for each week of analysis, $p<10^{-5}$.

Median MPOD values for each group throughout the supplementation period are shown in Fig. 2. Table 2 provides the average baseline MPOD and the average MPOD at week 24 for each of the three groups. When expressed as the rate of change of MPOD, milli-absorbance units/week (mAU/week) i.e. the average of the slopes of the regression lines through the MPOD values for each subject, mean rates of change were $1.92 \pm 1.43$, group $1,1.69 \pm 1.75$, group 2 , and $-0.75 \pm 3.03$, group $3, \mathrm{mAU} /$ week, respectively. See Table 3 and Fig. 3. The differences between the MPOD responses (rate of change of MPOD) for both the group 1, 2 and the group 3, the placebo (single tailed $t$-test) were highly significant but the differences between the group 1 and group 2 did not reach significance (two-tail $t$-test). 


\section{DISCUSSION}

\section{Serum responses}

The baseline serum concentration of the three groups ranged between 0.1 and $0.167 \mu \mathrm{g} / \mathrm{ml}$. The lutein concentration at baseline was significantly different between group 1 and group 3 but differences between groups 1 and 2 and groups 2 and 3 were not significant. In order to meaningfully compare the serum lutein responses obtained from all three groups the data were normalized to the baseline measurement for each as illustrated in Figure 1. Comparison of the response to the 24 week supplementation shows that increases in serum lutein were about $25 \%$ higher for group 1 compared to that of group 2. The $p$-value for the difference in the responses of these two groups was 0.066 (marginally significant).

\section{MPOD responses}

The MPOD responses of both groups 1 and 2, measured as rates of increase, were positive and significant. The median rate of increase in MPOD was $52 \%$ higher for group 1 compared with group 2 . The $p$-value for the difference in the MPOD responses was 0.09 (approaching significance). The mean rates of macular pigment increase did not differ significantly between group 1 and 2. In a study comprised of small groups and where the variability of the responses between subjects is inherently relatively large, the median can provide a useful perspective on the trend. Here we note that in group 1, which was given the diacetate formulation, the rate of increase in MPOD for the upper half of the subjects exceeded $2.35 \mathrm{mAU} /$ week and is well above the mean $(1.22 \times)$ whereas for those subjects consuming the lutein supplement the median rate was below the mean $(0.92 \times)$.

Many factors influence the measurement of bioavailability of a lutein supplement, including the normal intrinsic variability of responses between human subjects during a supplementation trial. The result is that responses of individuals are often spread over a significant range, indeed even qualitatively different responses are not rare, e.g. decreases versus increases in a measured quantity (Bone et al., 2003; Bone \& Landrum, 2010). Consequently, in studies such as the current investigation, care must be exercised to avoid over-interpretation. This small-scale pilot study demonstrates a trend toward larger responses for both serum lutein and MPOD to a micelle formulation of diacetate lutein relative to a supplement comprised of a crystalline suspension of lutein. A larger study is warranted to establish whether these responses observed here are significant and these trends are meaningful for a broader population.

\section{Acknowledgements}

Lutein supplements used in this study and funding were provided by Industrial Orgánica SA de CV.

\section{REFERENCES}

Benzie IF, Chung WY, Wang J, Richelle M, Bucheli P (2006) Enhanced bioavailability of zeaxanthin in a milk-based formulation of wolfberry (Gou Qi Zi; Fructus barbarum L.). Br J Nutr 96: 154160.

Bone RA, Landrum JT, Guerra L, H., Ruiz CA (2003) Lutein and zeaxanthin dietary supplements raise macular pigment density and serum concentration of these carotenoids. J Nutr 133: 992-998.

Bone RA, Landrum JT (2010). Dose-dependent response of serum lutein and macular pigment optical density to supplementation with lutein esters. Arch Biochem Biophys 504: 50-55.

Bowen P, Herbst-Espinosa S, Hussain E, Stacewicz-Sapuntzakis M (2002) Esterification does not impair lutein bioavailability in humans. J Nutr 132: 3668-3667.

Chung HY, Rasmussen HM, Johnson EJ (2004) Lutein bioavailability is higher from lutein-enriched eggs than from supplements and spinach in men. J Nutr 134: 1887-1893.

Granado F, Olmedilla B, Gil-Martinez E, Blanco I (1998) Lutein ester in serum after lutein supplementation in human subjects. Brit J Nutr 80: $445-449$.

Landrum JT, Bone RA, Joa H, Kilburn MD, Moore LL, Sprague KE (1997) A one year study of the macular pigment: the effect of 140 days of a lutein supplement. Exp Eye Res 65: 57-62.

Landrum JT, Bone RA (2001) Lutein, zeaxanthin, and the macular pigment. Arch Biochem Biophys 385: 28-40.

Mamatha BS, Baskaran V (2011) Effect of micellar lipids, dietary fiber and beta-carotene on lutein bioavailability in aged rats with lutein deficiency. Nutrition 27: 960-966.

Mares JA, Voland RP, Sondel SA, Millen AE, Larowe T, Moeller SM et al. (2011) Healthy lifestyles related to subsequent prevalence of agerelated macular degeneration. Arch Ophthalmol 129: 470—480.

Norkus EP, Norkus KL, Dharmarajan TS, Schierle J, Schalch W (2010) Serum lutein response is greater from free lutein than from esterified lutein during 4 weeks of supplementation in healthy adults. $J$ Am Coll Nutr 29: 575-585.

Olvera RM, Quiroga JT (2008) Absorption and bioavailability of carotenoids, formulations and applications. US patent, US 7,435,846. Industrial Organica, S.A. De C.V. .

Roodenburg AJC, Leenen R, van het Hof KH, Weststrate JA, Tijburg LBM (2000). Amount of fat in the diet affects bioavailability of lutein esters but not of alpha-carotene, beta-carotene, and vitamin $\mathrm{E}$ in humans. Am J Clin Nutr 71: 1187-1193.

SanGiovanni JP, Chew EY, Clemons TE, Ferris FL, 3rd, Gensler G, Lindblad AS et al., (2007). The relationship of dietary carotenoid and vitamin $\mathrm{A}, \mathrm{E}$, and $\mathrm{C}$ intake with age-related macular degeneration in a case-control study: AREDS Report No. 22. Arch Ophthalmol 125: 1225-1232.

Schalch W, Bone RA, Landrum JT (2010). The functional role of xathophylls in primate retina. In: Carotenoids: Physical, Chemical and Biological Functions and Properties. Landrum JT, ed, pp 257-282. CRC Press: Boca Raton. 
